\title{
The boundaries of privilege: elite English schools' geographies and depictions of a local community
}

\section{Rachel Brooks (University of Surrey) and Johanna Waters (University of Oxford)}

Elite schools are often perceived as having a strong international orientation. In part, this is related to the relatively large number of international pupils who attend them, their history of educating global elites, and their adoption of international curricula (such as the International Baccalaureate) (Hayden, 2011; Rizvi and Lingard, 2010). Nevertheless, in this chapter, we draw on an analysis of the websites, prospectuses and other publicly-available material from 30 elite schools in England, to argue that the geographical positioning of such schools is more complex. There is, for example, a clear tension between their need to depict a sense of elevation and 'apartness', on the one hand, and a desire to be involved (or to be seen to be involved) with activities outside their physical boundaries, on the other. In the chapter, we consider what an engagement with the 'local community' actually means for elite schools the extent to which they can be described as locally 'embedded', and whether the spaces and boundaries of the school (and thereby 'eliteness') are actually extended, albeit temporarily. The chapter speaks to debates in the sociology of education around the reproduction of privilege and in geography on understanding the spatalities of schooling.

\section{References}

Hayden M (2011) Transnational Spaces of Education: the growth of the international schools sector. Globalisation, Societies and Education 9 (2): 211-224.

Rivzi F and Lingard B (2010) Globalizing Educational Policy. London: Routledge. 